\title{
VAGINAL KERATINIZATION IN VITRO*
}

\author{
Raymond H. Kahn \\ Department of Anatomy, University of Michigan, Ann Arbor, Mich.
}

\section{Introduction}

The aim of this investigation is to determine the hormonal and/or nutritional factors responsible for the histological differentiation of epithelial tissues. The rodent vaginal epithelium is of special interest as a target organ for the study of such interrelationships because of its extreme sensitivity, both to vitamin-A deficiency and to estrogen administration. The process of vaginal keratinization produces a similar histological picture, whether caused by a deficiency of vitamin $\mathrm{A}$ or by estrogen administration. Vaginal keratinization may represent, however, a common end point for different histogenetic processes. ${ }^{1}$ Histological ${ }^{2-5}$ and histochemical ${ }^{6}$ studies on the role of vitamin $\mathrm{A}$ in vaginal keratinization lend support to the contention that vitamin A antagonizes the effect of estrogen in vivo. Furthermore, observations on integument in vivo ${ }^{7-14}$ and in vitro ${ }^{15-18}$ emphasize the role of vitamin A in epithelial differentiation.

In an attempt to determine specific hormone and vitamin actions, the technique of organ culture has been used. Organ culture ${ }^{19}$ involves the cultivation of fragments of organs or entire embryonic organs in a tissue-culture situation. Ultimately, one attempts to deal in vitro with normal tissue relationships as these exist in the body, divorced from the complexities of organ interaction.

\section{Method and Materials}

A modification of the watch-glass method ${ }^{20}$ as devised by Chen ${ }^{21}$ and Shaffer $^{22}$ was utilized so that cultures were grown on a synthetic (chemically defined) medium, namely, CMRL 1066. $\dagger$ The method entails the use of a closed candle chamber to produce a carbon dioxide atmosphere sufficient (approximately 5 per cent) to maintain the $p \mathrm{H}$ of the medium at 7.2 to 7.4 (FIGURE 1). The cultures, derived from 3- to 4-week-old Sprague-Dawley rats, were explanted on either rayon acetate $\ddagger$ or tantalum gauze $\S$ and incubated at $37^{\circ} \mathrm{C}$. from 1 to 6 days, having been subcultured every second day. Estradiol-17\%\| and crystalline vitamin-A alcohol $\uparrow$ were dissolved in absolute ethyl alcohol and serially diluted in the medium. The final concentration per watch glass was approximately $0.08 \mu \mathrm{g}$. of estradiol $-17 \beta(0.02 \mathrm{mg} . / 100 \mathrm{ml}$. medium), approximately $0.3 \mu \mathrm{g}$. of crystalline vitamin-A alcohol $(0.09 \mathrm{mg} . / 100 \mathrm{ml}$. medium), and a 0.1 per cent ethanol concentration. The same amount of ethanol was added to control cultures. Samples were fixed at daily intervals in formolacetic-alcohol and stained by the Regaud's iron hematoxylin Masson stain.

\footnotetext{
* The work reported in this paper was supported in part by the Institutional Research Grant and Grant P-124 of the American Cancer Society, New York, N. Y.

† Connaught Medical Research Laboratories, University of Toronto, Toronto, Canada.

‡ Voile, Silene, V. V. and Co., obtained through Robert Sayle and Co., Cambridge, England, and treated with Siliclad (Clay-Adams).

Ethicon, Inc., Type 50, Mesh 0.003 in., Code TM-53.

Nutritional Biochemical Corp., Cleveland, Ohio, Lot $\$ 4820$.

T Kindly supplied by R. E. Kent, Chas. Pfizer \& Co., Inc., Groton, Conn.
} 


\section{Results}

Prior to cultivation, the rodent vaginal epithelium appears as a stratified cuboidal epithelium varying in height from 5 to 10 cells. On occasion, the epithelium demonstrates evidence of an underlying squamous layer, possibly due to endogenous estrogens (FIGURE 2). Upon cultivation in the synthetic medium alone, the vaginal epithelium appears after 24 hours as a typical stratified squamous epithelium (FIGURE 3). After 48 hours in vitro, however, the epithelium begins to demonstrate keratinization of the underlying cells with progressive sloughing of the superficial cells (FIGURE 4). The addition of 0.08 $\mu \mathrm{g}$. of estradiol $-17 \beta$ per watch glass to the medium induces the precocious

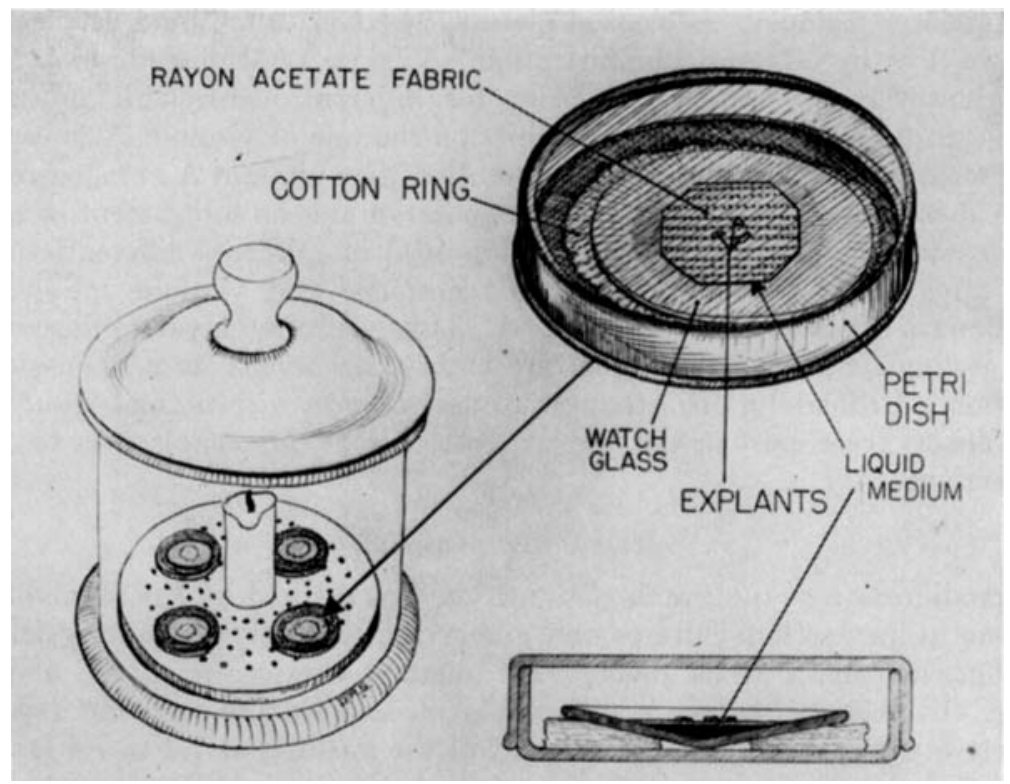

FIgURe 1.

development of keratinization after only 24 hours in vitro (FIGURE 5). Continued cultivation results in a greater degree of keratinization with concomitant loss of the thickness of the epithelium (FIGURE 6). The addition of vitamin-A alcohol to the medium ( $0.3 \mu \mathrm{g}$. per watch glass) results in a somewhat different situation. After 24 hours the epithelium continues to demonstrate the cuboidal nature of the superficial layer (FIGURE 7 ) seen in the controls, and remains so after 48 hours (FIGURE 8 ), but by the third day ( 72 hours) the epithelium again demonstrates the presence of keratinization (FIGURE 9).

\section{Discussion}

Whereas Emmens and Ludford ${ }^{23}$ were unsuccessful in their attempt to grow rodent vagina in vitro, Hardy et al. ${ }^{24}$ reported their success in growing fetal mouse vagina by the hanging-drop method, using a natural medium; they 


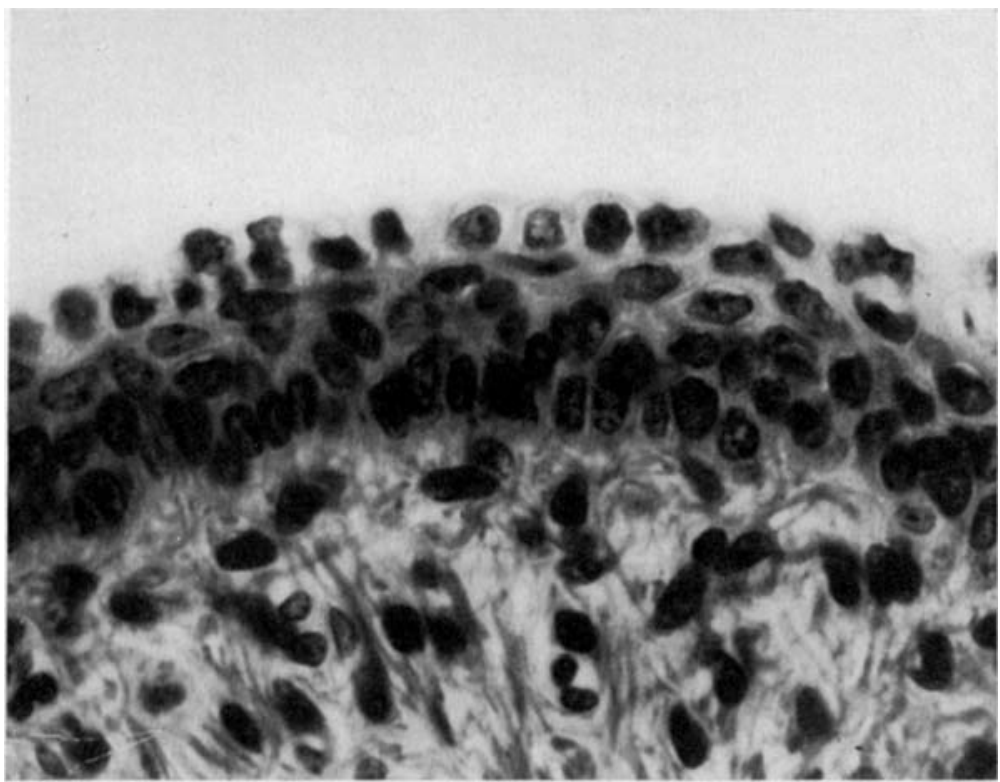

FIGURE 2. Section of vaginal mucosa of 3 -week-old rat, prior to cultivation. Note the squamous cells that are seen on occasion beneath the superficial cuboidal layer. $\times 650$.

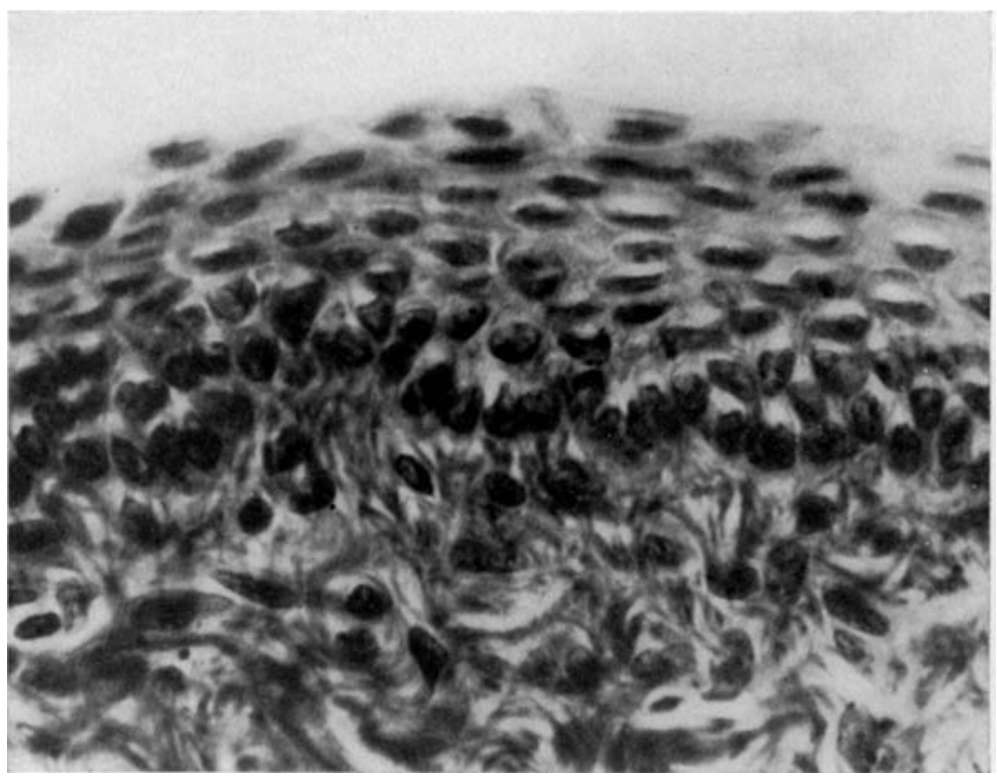

FIGURE 3. Section of vaginal mucosa of 3-week-old rat, cultured for 1 day in synthetic medium 1066. The epithelium is not keratinized. $\times 650$. 


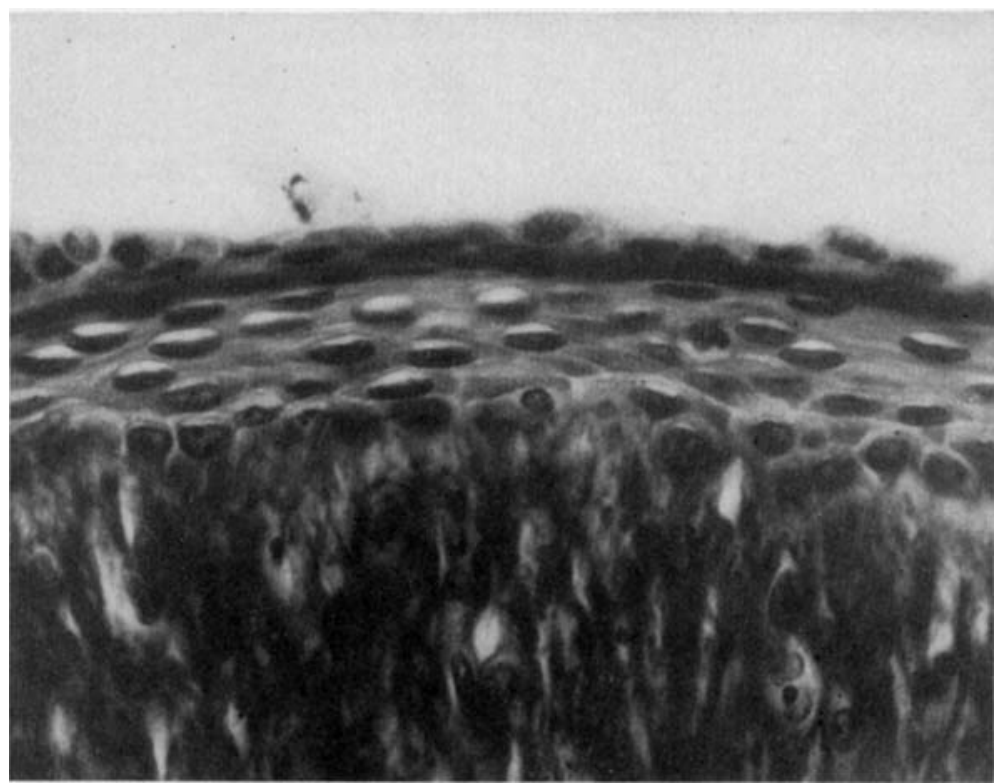

FigLRE 4. Section of vaginal mucosa of 3-week-old rat, cultured for 2 days in synthetic medium 1066. Keratinization present. $\times 650$.

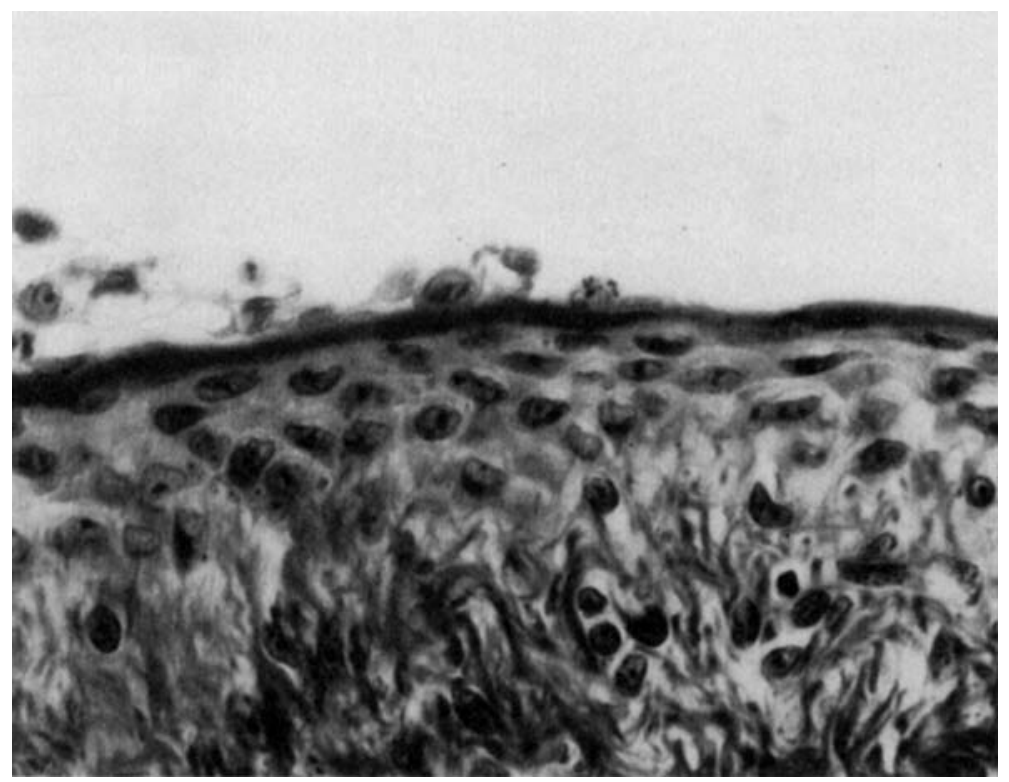

FIGURE 5. Section of vaginal mucosa of 3-week-old rat, cultured for 1 day in synthetic medium 1066 plus $0.08 \mu \mathrm{g}$. of estradiol-17\%. Note precocious keratinization. $\times 650$. 


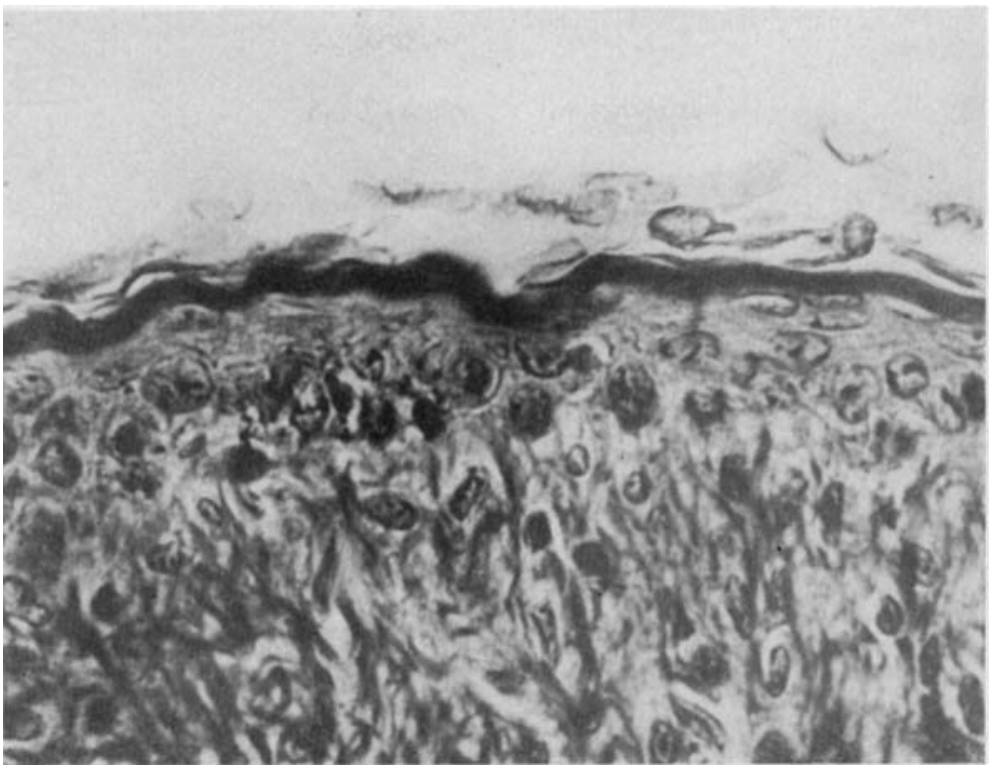

Figure 6. Section of vaginal mucosa of 3-week-old rat, cultured for 2 days in synthetic medium 1066 plus $0.08 \mu \mathrm{g}$. of estradiol- $17 \beta . \times 6.50$.

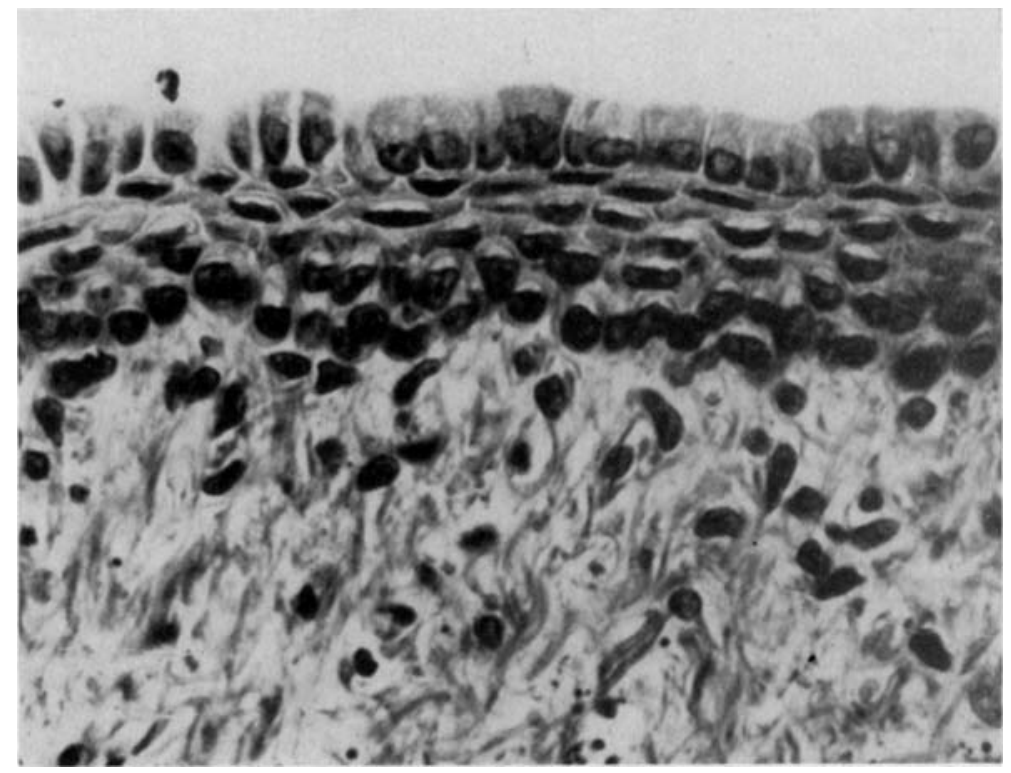

FIGURE 7. Section of vaginal mucosa of 3-week-old rat, cultured for 1 day in synthetic medium 1066 plus $0.03 \mu \mathrm{g}$. of crystalline vitamin-A alcohol. $\times 650$. 


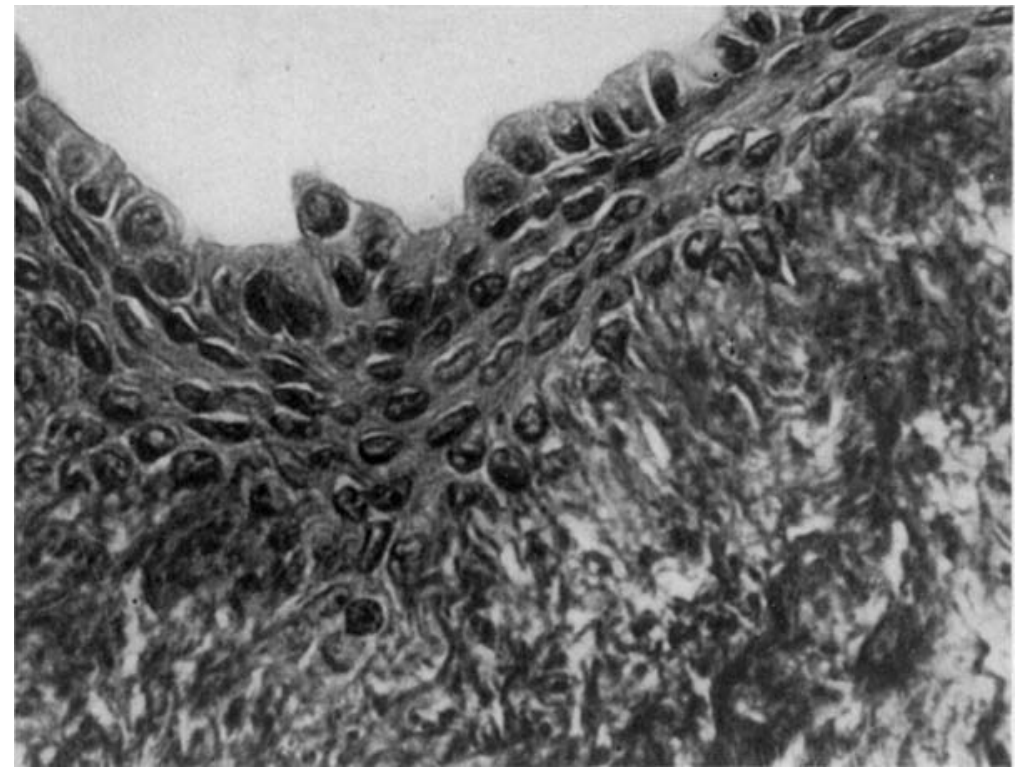

FigURE: 8. Section of vaginal mucosa of 3 -week-old rat, cultured for 2 day's in synthetic medium 1066 plus $0.03 \mu \mathrm{g}$. of crystalline vitamin-A alcohol. $\times 650$.

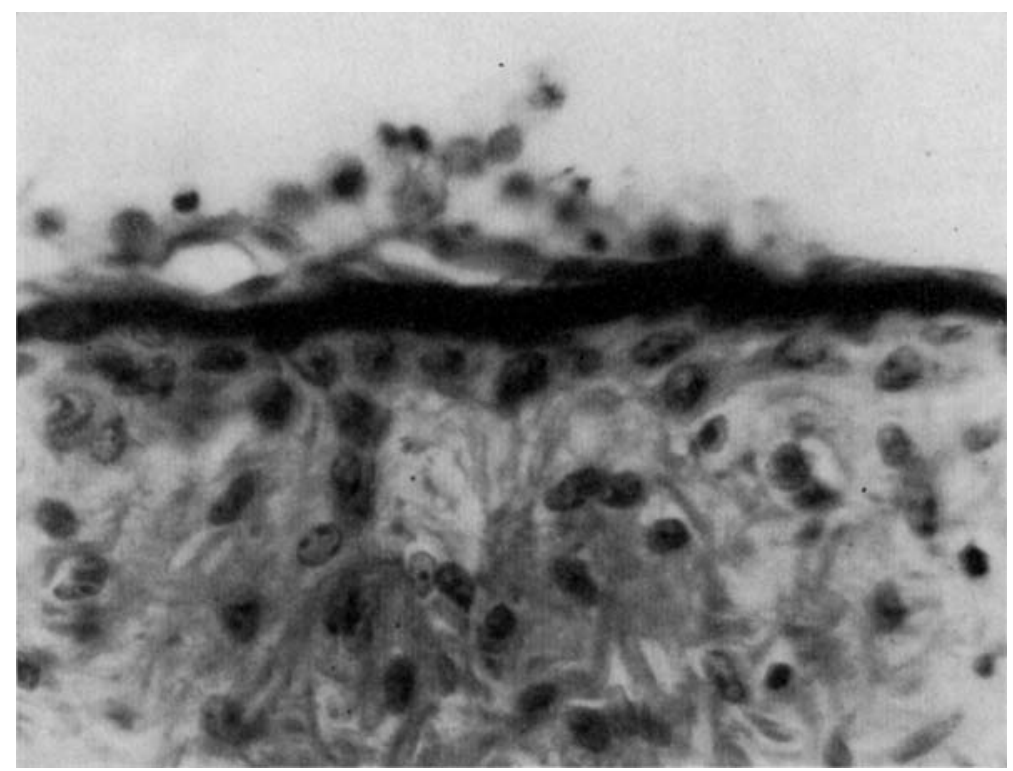

Frguke 9. Section of vaginal mucosa of 3 -week-old rat, cultured for 3 days in synthetic medium 1066 plus $0.03 \mu \mathrm{g}$. of crystalline vitamin-A alcohol. Keratinization present. $\times 650$. 
demonstrated that direct application of estrogens to the isolated vagina resulted in its keratinization, inferring therefrom that estrogens can act directly and are not metabolized systemically, as suggested by Szego and Roberts. ${ }^{25}$ We were similarly successful in the cultivation of the prepuberal rat vaginal epithelium, using the watch-glass method and a purely synthetic medium. Keratinization has been produced precociously by small amounts of estradiol$17 \beta$ added to the medium. Nevertheless, the local response to a steroid under the simplified conditions of organ culture may not be evoked in the same way as a systemically distributed folliculoid. Thus, these in vitro results in themselves do not exclude the possibility of metabolic activation of the steroid, as suggested by Szego and Roberts. ${ }^{25}$ It should be pointed out that the vaginal explants grown on the synthetic medium alone, used as controls, also underwent keratinization, although not as rapidly as those treated with the steroid. This keratinization of the controls can not be attributed, as previously suggested when natural media (embryonic extract and plasma) were used, ${ }^{4}$ to the presence of a factor(s) in the synthetic medium that specifically induces the phenomenon. It would appear that either the ability to keratinize is inherent in this tissue, as inferred by Moore, ${ }^{26}$ or the medium and conditions used in this investigation lack some specific requirement(s). Moore points out that the vaginal epithelium in an unstimulated state in vivo undergoes a type of cornification. The fact that vitamin A delays the onset of keratinization of the vaginal epithelium in vitro is indicative, although not conclusive, of its direct action to inhibit this phenomenon. Possibly other physical factors, such as oxygen tension, ${ }^{27}$ may be required to act synergistically with the vitamin on this tissue in vitro in order to corroborate the previous in vivo findings. ${ }^{2-6}$

Fell and Mellanby ${ }^{15}$ demonstrated that the addition of vitamin $\mathrm{A}$ to organ cultures of embryonic chick ectoderm not only inhibited keratinization but caused its differentiation into a mucus-secreting type. Weiss and James ${ }^{17,18}$ reported that only a brief exposure to the vitamin was necessary to inhibit keratinization of the embryonic chick ectoderm for a period of at least five days in vitro. They concluded that the vitamin was acting as a reversible inductor. Topically applying extremely small amounts of vitamin A to the skin of young adult mice, Lawrence and Bern ${ }^{14}$ were able to induce epidermal hypertrophy but could not establish any inhibition of keratinization.

It can be concluded only that the role of vitamin A in epithelial differentiation still remains obscure. However, the technique of organ culture as recently improved by Trowel ${ }^{27}$ provides a model system for further investigation of hormonal and nutritional actions.

\section{Summary}

A technique for the maintenance of the rodent vagina as an organized entity on a completely defined medium is described. Vaginal explants from prepuberal rats have been cultivated for from 1 to 6 days on a chemically defined synthetic medium (Connaught Medical Research Laboratories Medium * 1066) using the watch-glass technique. Vaginal epithelium in the medium alone keratinizes after 2 days in vitro. Addition of approximately $0.08 \mu \mathrm{g}$. of estradiol-17 $\beta$ per watch glass induced the precocious development of a cornified 
epithelium in 1 day. The addition of vitamin A ( $0.3 \mu \mathrm{g}$. per watch glass) inhibits, but does not prevent, keratinization in vitro. The implications of these findings are discussed briefly.

\section{Acknowledgment}

The technical assistance of Judith E. Lieding is greatly appreciated.

\section{References}

1. Bern, H. A., M. Alfert \& S. M. BlaIr. 1957. Cytochemical studies of keratin formation and of epithelial metaplasia in the rodent vagina and prostate. J. Histochem. 5: 105-119.

2. KAHN, R. H. \& H. A. BERN. 1950. Antifolliculoid activity of vitamin A. Science. 111: 516-517.

3. HoHlwes, W. 1951. Über die Hemmung der Oestrusrcaktirn ciech Vitamin- $\Lambda$ Überdosierung. Klin. Wochschr. 29: 193-195.

4. KAHN, R. H. 1954. Effect of oestrogen and of vitamin $A$ on vaginal cornification in tissue culture. Nature. 174: 317.

5. Hohlweg, W. \& U. LAschet. 1958. Vitamin A und Sexualzyklus. Vitamine u. Hormone. 8: 164-184.

6. KAHN, R. H. 1954. Effect of locally applied vitamin A and estrogen on the rat vagina. Am. J. Anat. 95: 309-335.

7. Flesch, P. 1952. Inhibition of keratin formation with unsaturated compounds. J, Invest. Dermatol. 19: 353-363.

8. FLESCH, P. 1953. Studies on the mode of action of vitamin A. J. Invest. Dermatol. 21: $421-434$.

9. FitfSCH, P. \& S. B. GoLDSTONE. 1952. Local depilatory action of unsaturated compounds; the effect of human sebum on hair growth. J. Invest. Dcrmatol. 18: 267287.

10. Bern, H. A., J. J. Elias, P. B. Pickett, T. R. Powers \& M. N. Harkness. 1955. The: influence of vitamin $A$ on the epidermis. Am. J. Anat. 96:419-447.

11. Studer, A. \& J. R. Frey. 1949. U̇ber Hautveränderungen der Ratte nach grossen oralen Dosen von Vitamin A. Schweiz. med. Wochschr. 79: 382-384,

12. Studer, A. \& J. R. Frey. 1952. Wirkung von Cortison auf die ruhende und die mit Vitamin A oder Testosteronpropionat zur Proliferation gebrachte Epidermis der Ratte. Dermatologica. 104: 1-18.

13. Stupfr, A. 1953. Zur Frage der Angriffsorte von Compound E (Cortison). Fine experimentelle Studie. Z. ges. exptl. Med, 121: 287-418.

14. Lawrence, D. J. \& H. A. BERn. 1958. On the specificity of the response of mouse epidermis to vitamin A. J. Invest. Dermatol. 31(6): 313-325.

15. Fell, H. B. \& E. Mellanby. 1953. Metaplasia produced in cultures of chick ectoderm by high vitamin A. J. Physiol. 119: 470-488.

16. Fell, H. B., E. Mellanby \& S. R. Pelc. 1954. Influence of excess vitamin A on the sulphate metabolism of chick ectoderm grown in vitro. Brit. Med. J. 2: 611.

17. WEISS, P. \& R. JAMES. 1954. Vitamin A and skin keratinization in vitro: experimental dissociation of induction and realization phases in cytodifferentiation. Science. 119: 587.

18. WeIss, P. \& R. JAMEs. 1955. Skin metaplasia in vitro induced by brief exposure to vitamin A. Exptl. Cell Research. Suppl. 3: 381-394.

19. Strangeways, T. S. P. \& H. B. FeLL. 1926-1927. Experimental studies on the cilfferentiation of embryonic tissues growing in vivo and in vitro. Proc. Roy. Soc. london. B99: 340-366.

20. Fell, H. B. \& R, Robison. 1929. The growth, development and phosphatase activity of embryonic avian femora and limb-buds cultivated in vitro. Biochem. J. 23: 767784.

21. Chen, J. M. 1954. The cultivation in fluid medium of organised liver, pancreas, and other tissues of foetal rats. Exptl. Cell Research. 7: 518-529.

22. Shaffer, B. M. 1956. The culture of organs from the embryonic chick on celluloseacetate fabric. Exptl. Cell Research. 11: 244-248.

23. Emmens, C. W. \& R. J. Ludford. 1940. Action of oestrogens on the female genita! tract. Nature. 145: 746-747. 
24. Hardy, M. H., J. D. Buggers \& P. J. Clartngbold. 1953. Vaginal comification of the mouse produced by oestrogens in vitro. Nature. 172: 1196-1197.

25. Szego, C. M. \& S. Roberts. 1953. Steroid action and interaction in uterine metabolism. Recent Progr. in Hormone Research. 8: 419-469.

26. MOORE, T. 1957. Vitamin A. Elsevier. Amsterdam, Holland.

27. Troweld, O. A. 1959. The culture of mature organs in a synthetic medium. Exptl. Cell Research. 16: 118-147. 